\title{
Equilibrium State of Anatase to Rutile Transformation for Titanium Dioxide Film Prepared by Ultrasonic Spray Pyrolysis Technique
}

\author{
Ghassem Kavei $^{1,2}$, Auppatham Nakaruk ${ }^{2}$, Charles Chris Sorrell ${ }^{2}$ \\ ${ }^{1}$ Materials and Energy Research Centre, Tehran, Iran; ${ }^{2}$ School of Materials Science and Engineering University of New South Wales, \\ Sydney, Australia. \\ Email: g-kavei@merc.ac.ir, prof.kavei@hotmail.com
}

Received November $26^{\text {th }}, 2010$; revised December $25^{\text {th }}, 2010$; accepted May $9^{\text {th }}, 2011$.

\begin{abstract}
Titanium dioxide thin films were deposited on (0001) $\alpha$-quartz substrate by spray pyrolysis method. The method which an aerosol of Titanium Butoxide, generated ultrasonically, was sprayed on the substrate at temperature of $400^{\circ} \mathrm{C}$, kept at this temperature for periods of 3,13,19 and 39 hours. The developed films at a crystal phase correspond to the $\mathrm{TiO}_{2}$ anatase and rutile phases. Their surface roughness increased by annealing the samples at 600,800 and $1000^{\circ} \mathrm{C} . \mathrm{De}-$ posited film annealed at $1000^{\circ} \mathrm{C}$ showed preferable orientation in (110) direction. The crystal evolution and crystallographic properties of this material was studied by Lotgering method, X-ray Diffraction (XRD) and Scanning Electron Microscopy (SEM). The study revealed that the deposition process was nearly close to the classical Chemical Vapour Deposition (CVD) technique that is generally employed to produce films with smooth surface and good crystalline properties with a thickness of about $1 \mu \mathrm{m}$, as measured by Focused Ion Beam.
\end{abstract}

Keywords: Titanium Dioxide, Ultrasonic Spray Pyrolysis, Annealing Treatment, Phase Transformation, Focused Ion $\operatorname{Beam}(F I B)$

\section{Introduction}

In the past decade, considerable efforts were made to synthesize self-cleaning materials, especially titanium dioxide $\left(\mathrm{TiO}_{2}\right.$ or titania). Basically, for self-cleaning application, titania can be used in various forms such as powder, [1] thin film [2-4] and thick films [5]. However, thin and thick films are most commonly used due to their flexible and applicable properties. Furthermore, titania film can be employed as gas sensors [6] purifier of environmental pollutants [7], photovoltaics and photocatalysis [8-10]. Therefore, plenty of literature reviews had paid attention to thin or thick film coating methods such as magnetron sputtering [11], Pulsed Laser Deposition (PLD) [12], Chemical Vapour Deposition (CVD) [13], sol-gel [6], gel oxidation [14], screen printing [15], anodic oxidation [16], and electrophoretic deposition [17]. Titanium oxide films are prepared by an ultrasonic nebulization and pyrolysis technique developed by $[18,19]$.

For self-cleaning applications, a titania film with small band gap and large surface area (small grain size) is required. However, it is known that anatase phase will pro- vide small grain size, but the band gap of the product is greater than that of rutile. On the other hand, rutile phase has smaller band gap but the resultant grains are larger compared to anatase. Having this point in mind, one can conclude that an intermediate phase between anatase and rutile probably benefits from both small band gap and moderate grain size and is advantageous for self-cleaning materials.

It is well known that titanium dioxide consists of three phases: brookite, anatase, and rutile [20]. Generally, anatase will transform into rutile at $\sim 600^{\circ} \mathrm{C}$, [21]. However, in thin film, the anatase temperature transformation to rutile can rise up to $900^{\circ} \mathrm{C}$ [22].

This study has been designed to confirm the formation of a film with mixed phase of anatase and rutile structures at $400^{\circ} \mathrm{C}$. This was verified by inspecting the variation of effective parameters (such as time, substrate and annealing temperature) on the samples.

\section{Methodology}

Ultrasonic spray pyrolysis was used to provide fully- 
dense anatase and rutile thin films. The precursor material (A starting solution) was prepared from titanium $\mathrm{Bu}-$ toxide ([Ti $\left.\left(\mathrm{OCH}_{2} \mathrm{CH}_{2} \mathrm{CH}_{2} \mathrm{CH}_{3}\right)_{4}\right]$, Reagent Grade $97 \mathrm{wt} \%$, Sigma-Aldrich) dissolved in methanol (Reagent Plus $\geq$ $99 \mathrm{wt} \%$, Sigma-Aldrich) at a titanium concentration of $0.5 \mathrm{M}$. The aerosol as a mist was produced by means of a generic ultrasonic generator of $1.7 \mathrm{MHz}$ frequency. Compressed air at pressure of $1.3 \mathrm{~atm}$ was admitted through a shape tube ( $\cap$ shape, $12 \mathrm{~cm}$ in diameter) to align mist molecules and direct molecules toward substrate. This causes the molecules to be deposited uniformly on the substrate. The substrate was $(0001) \alpha$-quartz $(1 \times 20 \times 20$ $\mathrm{mm}$ ) heated at a constant temperature up to $400^{\circ} \mathrm{C}$ for 3 34 hours during the deposition process using a commercial hotplate (SEM heater equipped with thermodigital controller). Deposited $\mathrm{TiO}_{2}$ films were annealed in air at $600^{\circ} \mathrm{C}, 800^{\circ} \mathrm{C}$, and $1000^{\circ} \mathrm{C}$ for $7 \mathrm{~h}$, at a heating rate of $5^{\circ} \mathrm{C}$ per minute, followed by a natural cooling process overnight.

$\mathrm{TiO}_{2}$ films were characterised by the following techniques: 1) Mineralogy and phase analysis of the films was examined using laser Raman microspectroscopy with a $514 \mathrm{~nm}$ Ar laser integrated with an optical microscope (Renishaw in via), 2) the structures were defined via glancing angle $\mathrm{X}$-ray diffraction (GAXRD, angle of incidence $1^{\circ}$, penetration depth $<300 \mathrm{~nm}$, Phillips X'pert Materials Research Diffraction), and standard X-ray powder diffraction $\left(\mathrm{XRD}, 20^{\circ}-80^{\circ} 2 \theta\right.$, speed $0.02^{\circ} 2 \theta / \mathrm{s}$, step $0.01^{\circ} 2 \theta$, scans done in situ, Phillips X'pert Multipurpose X-ray Diffraction System) (MPD-Shurr) with 45 $\mathrm{kV}$ and $40 \mathrm{~mA}$ cathode voltage and current, respectively. As a result, $\mathrm{Cu}_{\mathrm{K} \alpha}$ line radiation $(\lambda=1.5405 \AA)$ was obtained. 3) Surface morphology was evaluated by Field Emission Scanning Electron Microscopy (FESEM) using Hitachi (S4500X) model. 4) Film thickness was determined using single-beam focused ion beam (FIB) milling (FEI XP200). In this system, a voltage of $30 \mathrm{kV}$ was applied between the sample and probe, leading to a current of $64 \mathrm{pA}$. Gallium ions $\left(\mathrm{Ga}^{3+}\right)$ were used to erode a square hole in the film and an image of the cross-section of the layers was viewed at an angle of $45^{\circ}$. To perform SEM and FIB measurements, samples were coated with $\sim 20 \mathrm{~nm}$ thick gold $(\mathrm{Au})$ layer using sputtering technique.

\section{Results and Discussion}

Figure 1 show XRD patterns of titania films deposited on the substrate. Table 1 also summarises the list of peaks from XRD data. It can be seen that as-deposited film at $400^{\circ} \mathrm{C}$ consists of anatase and rutile phases of titanium dioxide. There is a strong peak of anatase at (101) plan with $2 \theta=25.50^{\circ}$ and a small peak of rutile at (110) with $2 \theta=27.58^{\circ}$. After annealing at $600^{\circ} \mathrm{C}$ and $800^{\circ} \mathrm{C}$ for
$7 \mathrm{~h}$, the XRD patterns suggested that the rutile phase was dominated. At annealing temperature of $1000^{\circ} \mathrm{C}$, anatase was totally transformed into rutile.

Roughly speaking, anatase phase transformation into rutile occurs at $\sim 600^{\circ} \mathrm{C}$ in titania powder [21]. Transformation temperature rises up to $\sim 900^{\circ} \mathrm{C}$ in the case of titania film [22]. Figure 2 shows XRD pattern of samples being deposited in the substrate at $400^{\circ} \mathrm{C}$ with various durations, $3-24$ hours. As depicted in this figure, the patterns of $\mathrm{TiO}_{2}$ films are similar and contain anatase phase. This implies that the nature of rutile phase formed on as-deposited film does not change with temperature du- ration. If a fixed substrate temperature had any direct effect on the phase transformation of the $\mathrm{TiO}_{2}$ film, the rutile phase would elevate after the long duration that the films had been kept at a defined temperature (here is $400^{\circ} \mathrm{C}$ ) (see Figure 2). Therefore, the possible reason for development of rutile phase in as-deposited film might be a kinetic energy in $\mathrm{TiO}_{2}$ film for phase stabilisation at particular temperature. In other words, the structural transformation is greatly designated for an annealing temperature and is almost independent of annealing duration; a period which is not definitely longer than 7 hours as far as titania is concerned (see Figure 1).

Figure 3 shows the surface morphology of $\mathrm{TiO}_{2}$ films at different annealing temperatures. Comparing the images of as-deposited film and annealed film at $600^{\circ} \mathrm{C}$ revealed that the film contained anatase phase (with small grain size $\sim 100 \mathrm{~nm}$ ) and rutile phase (with large grain size $\sim 500 \mathrm{~nm}$ ).

Annealing temperature increment densifies rutile phase. These results confirmed by XRD patterns depicted in Figure 1 in which the as-deposited film and annealed film at $600^{\circ} \mathrm{C}$ consisted of both anatase and rutile phases. After annealing at $800^{\circ} \mathrm{C}$ for $7 \mathrm{~h}$, the surface morphology showed that rutile phase is dominant. When annealed at $1000^{\circ} \mathrm{C}$, the film contained no anatase, implying that anatase had completely turned into rutile with the average grain size of $\sim 500 \mathrm{~nm}$.

Since annealing process does not affect the film thickness, as reported by, [23] the FIB photograph of the as-deposited film in Figure 4 represents the thickness of all $\mathrm{TiO}_{2}$ films. As illustrated in the figure, thickness of as-deposited film was constantly $\sim 1 \mu \mathrm{m}$. Furthermore, the grain size of anatase-rutile intermediate phase can be seen in FIB image. More detailed analysis for the experimental results was studied, and basic mechanisms are given for anatase to routile transformation analysis [19].

\section{Conclusions}

$\mathrm{TiO}_{2}$ thin films with smooth surface and crystalline structure were obtained by pyrolysing an ultrasonically 


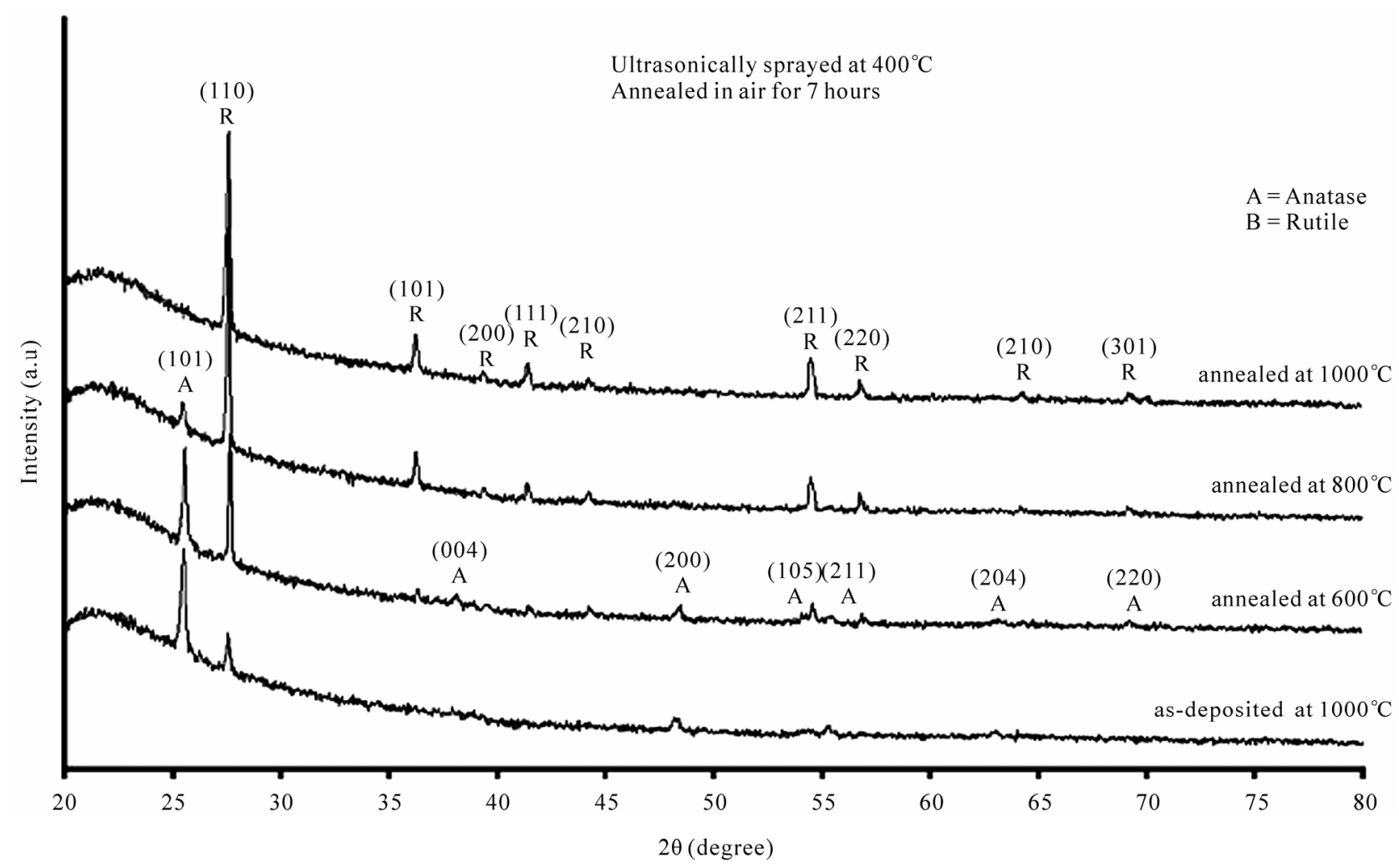

Figure 1. XRD patterns of titania films prepared by ultrasonic spray pyrolysis at $400^{\circ} \mathrm{C}$ for $3 \mathrm{~h}$, and annealed at temperature range of $600^{\circ} \mathrm{C}$ to $1000^{\circ} \mathrm{C}$ for $7 \mathrm{~h}$.

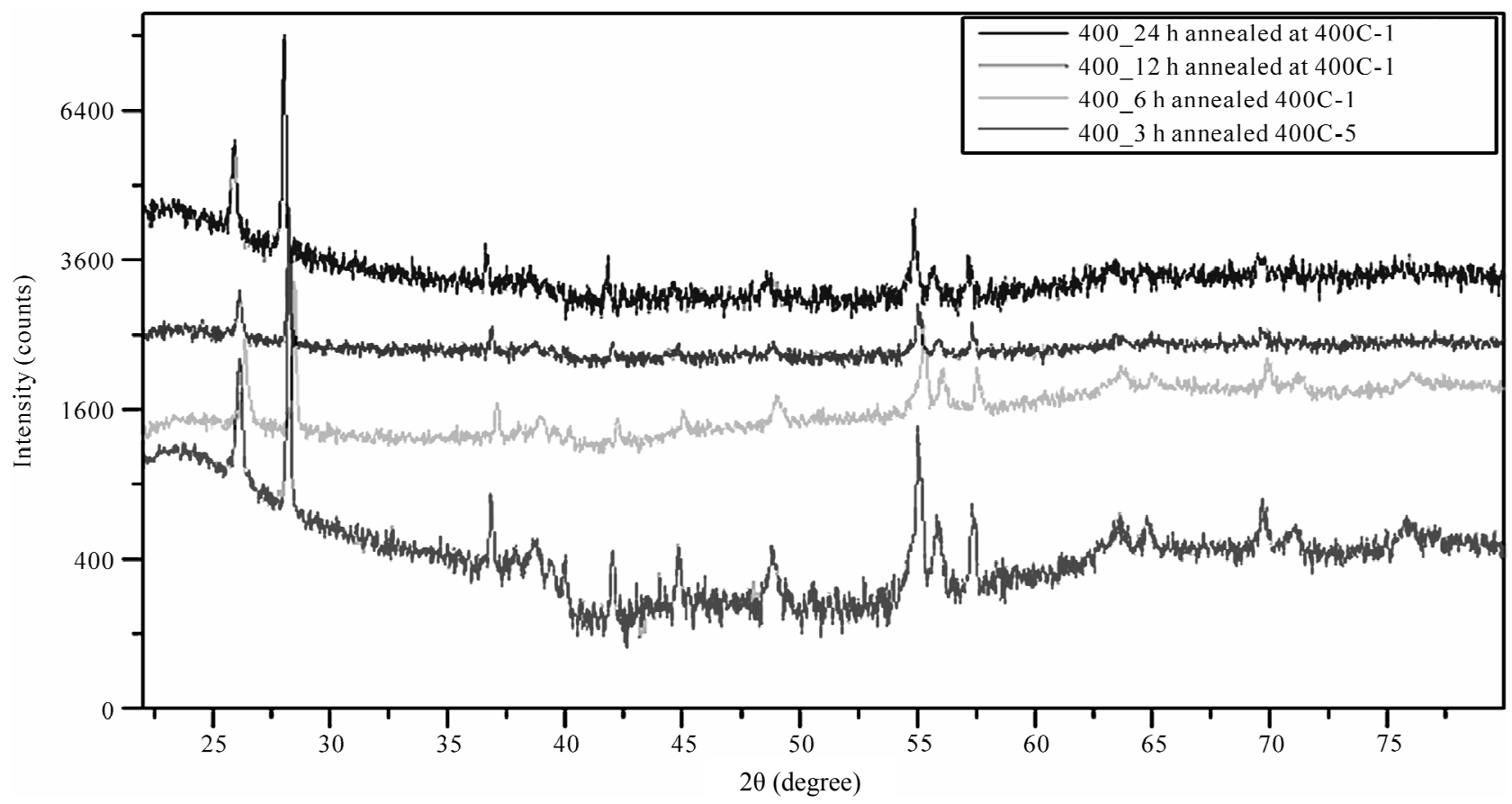

Figure 2. XRD patterns of the film after deposition on the substrate at $400^{\circ} \mathrm{C}$ for three hours the temperature of substrate was kept at $400^{\circ} \mathrm{C}$ for stabilization of the coated compounds with various durations (modified and raw spectra), (a) flattened; (b) as recorded. 

Film Prepared by Ultrasonic Spray Pyrolysis Technique

Table 1. Comparison between experimental (Film) and reported (Powder) $2 \theta$ peak positions from X-ray diffraction data for anatase and rutile.

\begin{tabular}{|c|c|c|c|c|c|c|c|}
\hline \multirow{2}{*}{$\begin{array}{c}\mathrm{TiO}_{2} \\
\text { Polymorph }\end{array}$} & \multirow{2}{*}{ Plane } & \multicolumn{4}{|c|}{ Annealing } & \multirow{2}{*}{ Literature } & \multirow{2}{*}{ Reference } \\
\hline & & None & $600^{\circ} \mathrm{C}$ & $800^{\circ} \mathrm{C}$ & $1000^{\circ} \mathrm{C}$ & & \\
\hline \multirow{8}{*}{ Anatase } & (101) & 25.50 & 25.52 & 25.50 & & 25.31 & \multirow{8}{*}{$\begin{array}{c}\text { JCPDS } \\
71-1166\end{array}$} \\
\hline & (004) & & 38.02 & & & 37.79 & \\
\hline & $(200)$ & 48.38 & 48.40 & & & 48.05 & \\
\hline & (105) & 54.20 & 54.21 & & & 53.89 & \\
\hline & (211) & 55.34 & 55.42 & & & 55.07 & \\
\hline & (204) & & & & & 62.69 & \\
\hline & $(220)$ & & & & & 70.30 & \\
\hline & (215) & & & & & 75.05 & \\
\hline \multirow{10}{*}{ Rutile } & (110) & 27.58 & 27.63 & 27.57 & 27.57 & 27.43 & \multirow{10}{*}{$\begin{array}{c}\text { JCPDS } \\
72-1148\end{array}$} \\
\hline & (101) & & 36.31 & 36.23 & 36.23 & 36.08 & \\
\hline & $(200)$ & & & 39.41 & 39.42 & 39.19 & \\
\hline & (111) & & 41.48 & 41.38 & 41.41 & 41.24 & \\
\hline & (210) & & 44.25 & 44.27 & 44.21 & 44.04 & \\
\hline & (211) & & 54.54 & 54.46 & 54.46 & 54.32 & \\
\hline & $(220)$ & & 56.82 & 56.80 & 56.82 & 56.62 & \\
\hline & $(310)$ & & & & 64.29 & 64.04 & \\
\hline & (301) & & & & 68.25 & 68.99 & \\
\hline & (112) & & & & 70.03 & 69.79 & \\
\hline
\end{tabular}

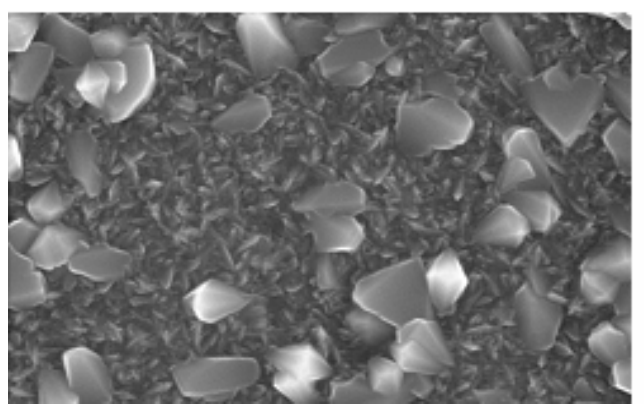

As-deposited at $400^{\circ} \mathrm{C}$

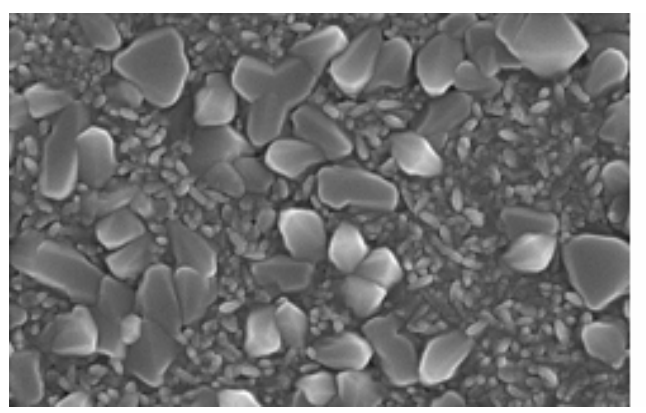

Annealed at $800^{\circ} \mathrm{C}$

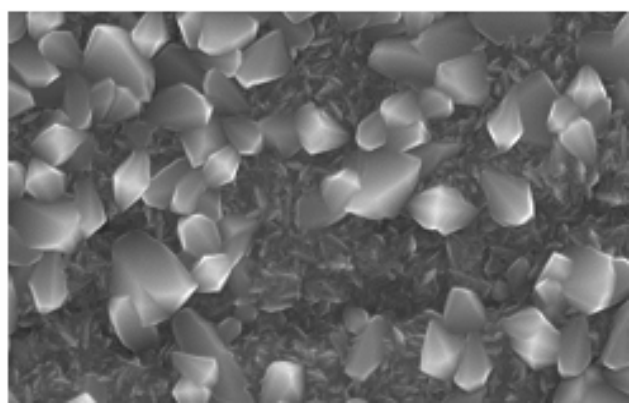

Annealed at $600^{\circ} \mathrm{C}$

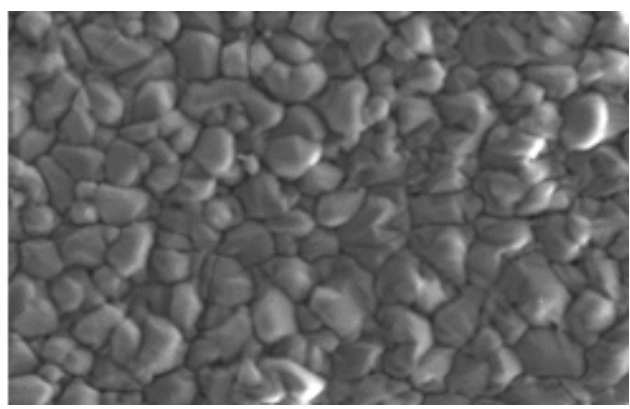

Annealed at $1000^{\circ} \mathrm{C}$

\section{$3 \mu \mathrm{m}$}

Figure 3. SEM images of the $\mathrm{TiO}_{2}$ films surface showing morphology of the surfaces at different annealing temperatures. 


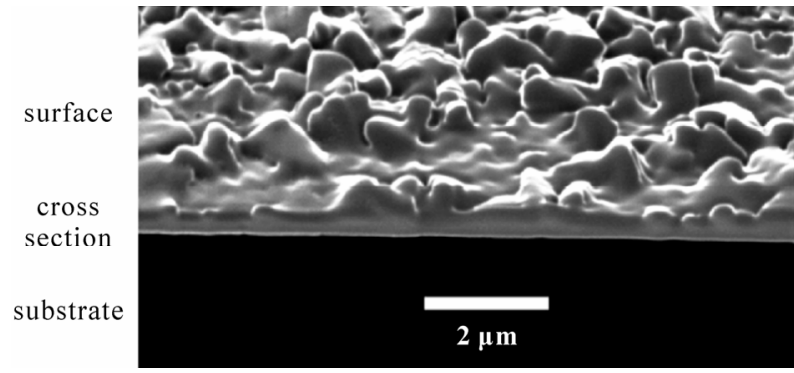

Figure 4. Thickness of as-deposited film (measured to be 1 $\mu \mathrm{m}$ by FIB).

generated aerosol of Titanium (IV) Tert-Butoxide. Crystal structure analysis, granular morphology and surface roughness of as-deposited films and structure escalation of once-annealed samples, revealed that the growth process is closer to chemical vapour deposition rather than to the typical splashing mechanisms of spray pyrolysis technique. Substrate temperature maintained at $400^{\circ} \mathrm{C}$. At higher temperatures, evolution of rutile phase was significant. The developed surface showed different magnitudes of the rutile phase intensity depending on annealing temperatures. A crystalline phase of outstanding transition to rutile was occurred when samples were annealed at $1000^{\circ} \mathrm{C}$.

\section{Acknowledgements}

The first author thanks the Ministry of Science, Research \& Technology of Iran for giving him the chance to sabbatical leave. Also, the authors are grateful for the financial support of Austral Brick Co. Pty. Ltd., which allowed these and other researches in this category to be undertaken.

\section{REFERENCES}

[1] D. Dvoranová, V. Brezová, M. Mazúr and M. A. Malati, "Investigations of Metal-Doped Titanium Dioxide Photocatalysts," Applied Catalysis B: Environmental, Vol. 37, No. 2, 2002, pp. 91-105. doi:10.1016/S0926-3373(01)00335-6

[2] T. Miyagi, M. Kamei, T. Ogawa, T. Mitsuhashi, A. Yamazaki and T. Sato, "Pulse Mode Effects on Crystallization Temperature of Titanium Dioxide Films in Pulse Magnetron Sputtering," Thin Solid Films, Vol. 442, No. $1-2,2003$, pp. 32-35. doi:10.1016/S0040-6090(03)00934-9

[3] A. Mills, G. Hill, S. Bhopal, I. P. Parkin and S. A. O'Neill, "Thick Titanium Dioxide Films for Semiconductor Photocatalysis," Journal of Photochemistry and Photobiology A, Vol. 160, No. 3, 2003, pp. 185-194. doi:10.1016/S1010-6030(03)00206-5

[4] T. Watanabe, A. Nakajima, R. Wang, M. Minabe, S. Koizumi, A. Fujishima and K. Hashimoto, "Photocatalytic
Activity and Photoinduced Hydrophilicity of Titanium Dioxide Coated Glass," Thin Solid Films, Vol. 351, No. $1-2,1999$, pp. 260-263. doi:10.1016/S0040-6090(99)00205-9

[5] T. Nonami, H. Hase and K. Funakoshi, "Apatite-Coated Titanium Dioxide Photocatalyst for Air Purification," Catalysis Today, Vol. 96, No. 3, 2004, pp. 113-118. doi:10.1016/j.cattod.2004.06.112

[6] C. Garzella, E. Comini, E. Tempesti, C. Frigeri and G. Sberveglieri, "TiO 2 Thin Films by a Novel Sol-Gel Processing for Gas Sensor Applications," Sensors and Actuators B, Vol. 68, No. 1-3, 2000, pp. 189-196. doi:10.1016/S0925-4005(00)00428-7

[7] H. Ichiura, T. Kitaoka and H. Tanaka, "Removal of Indoor Pollutants under UV Irradiation by a Composite $\mathrm{TiO}_{2}$-Zeolite Sheet Prepared Using a Papermaking Technique," Chemosphere, Vol. 50, No. 1, 2003, pp. 79-83. doi:10.1016/S0045-6535(02)00604-5

[8] T. Bak, J. Nowotny, M. Rekas and C. C. Sorrell, "Photoelectrochemical Hydrogen Generation from Water Using Solar Energy," International Journal of Hydrogen Energy, Vol. 27, No. 10, 2002, pp. 991-1022.

doi:10.1016/S0360-3199(02)00022-8

[9] T. Bak, J. Nowotny, M. Rekas and C. C. Sorrell, "PhotoElectrochemical Properties of the $\mathrm{TiO}_{2}-\mathrm{Pt}$ System in Aqueous Solutions," International Journal of Hydrogen Energy, Vol. 27, No. 1, 2002, pp. 19-26. doi:10.1016/S0360-3199(01)00090-8

[10] J. Nowotny, C. C. Sorrell, L. R. Sheppard and T. Bak, "Solar-Hydrogen: Environmentally Safe Fuel for the Future," International Journal of Hydrogen Energy, Vol. 30, No. 5, 2005, pp. 521-544. doi:10.1016/i.ijhydene.2004.06.012

[11] T. Miyagi, M. Kamei, T. Ogawa, T. Mitsuhashi, A. Yamazaki and T. Sato, "Pulse Mode Effects on Crystallization Temperature of Titanium Dioxide Films in Pulse Magnetron Sputtering," Thin Solid Films, Vol. 442, No. 1-2, 2003, pp. 32-35. doi:10.1016/S0040-6090(03)00934-9

[12] Y. Suda, H. Kawasaki, T. Ueda and T. Ohshima, "Preparation of High Quality Nitrogen Doped $\mathrm{TiO}_{2}$ Thin Film as a Photocatalyst Using a Pulsed Laser Deposition Method," Thin Solid Films, Vol. 453-454, 2004, pp. 162-166. doi:10.1016/j.tsf.2003.11.185

[13] H. Sun, C. Wang, S. Pang, X. Li, Y. Tao, H. Tang and M. Liu, "Photocatalytic $\mathrm{TiO}_{2}$ Films Prepared by Chemical Vapor Deposition at Atmosphere Pressure," Journal of Non-Crystalline Solids, Vol. 354, No. 12-13, 2008, pp. 1440-1443. doi:10.1016/j.jnoncrysol.2007.01.108

[14] H. Z. Abdullah and C. C. Sorrell, "Preparation and Characterisation of $\mathrm{TiO}_{2}$ Thick Films by Gel Oxidation," Materials Science Forum, Vol. 561-565, 2007, pp. 2167-2170.

[15] I. Seigo, P. Chen, P. Comte, M. K. Nazeeruddin, P. Liska, P. Péchy and M. Grätzel, "Fabrication of Screen-Printing Pastes from $\mathrm{TiO}_{2}$ Powders for Dye-Sensitized Solar Cells," Progress in Photovoltaics: Research and Applica- 
tions, Vol. 15, No. 7, 2007, pp. 603-609.

doi:10.1002/pip.768

[16] H. Z. Abdullah and C. C. Sorrell, "Preparation and Characterisation of $\mathrm{TiO}_{2}$ Thick Films Fabricated by Anodic Oxidation," Materials Science Forum, Vol. 561-565, 2007, pp. 2159-2162.

[17] H. Z. Abdullah and C. C. Sorrell, "Preparation and Characterisation of $\mathrm{TiO}_{2}$ Thick Films Fabricated by Electrophoretic Deposition," Materials Science Forum, Vol. 561-565, 2007, pp. 2163-2166.

[18] W. Xu, R. Kershaw, K. Dwight and A. Wold, "Preparation and Characterization of $\mathrm{TiO}_{2}$ Films by a Novel Spray Pyrolysis Method," Materials Research Bulletin, Vol. 25, No. 11, 1990, pp. 1385-1392. doi:10.1016/0025-5408(90)90221-M

[19] A. Nakaruk, D. Ragazzon and C. C. Sorrell, "Anatase-Rutile Transformation through High-Temperature Annealing of Titania Films Produced by Ultrasonic Spray Pyrolysis," Thin Solid Films, Vol. 518, No. 14, 2010, pp. 3735-3742. doi:10.1016/j.tsf.2009.10.109
[20] D. Reyes-Coronado, G. Rodríguez-Gattorno, M. E. Espinosa-Pesqueira, C. Cab, R. de Coss and G. Oskam, "Phase-Pure $\mathrm{TiO}_{2}$ Nanoparticles: Anatase, Brookite and Rutile," Nanotechnology, Vol. 19, No. 14, 2008, pp. 145605-145614. doi:10.1088/0957-4484/19/14/145605

[21] L. E. Depero, P. Bonzi, M. Zocchi, C. Casale and G. De Michele, "Study of the Anatase-Rutile Transformation in $\mathrm{TiO}_{2}$ Powders Obtained by Laser-Induced Synthesis," Journal of Materials Research, Vol. 8, No. 10, 1993, pp. 2709-2715. doi:10.1557/JMR.1993.2709

[22] D. J. Kim, S. H. Hahn, S. H. Oh and E. J. Kim, "Influence of Calcination Temperature on Structural and Optical Properties of $\mathrm{TiO}_{2}$ Thin Films Prepared by Sol-Gel Dip Coating," Materials Letters, Vol. 57, No. 2, 2002, pp. 355-360. doi:10.1016/S0167-577X(02)00790-5

[23] N. Martin, C. Rousselot, D. Rondot, F. Palmino and R. Mercier, "Microstructure Modification of Amorphous Titanium Oxide Thin Films during Annealing Treatment," Thin Solid Films, Vol. 300, No. 1-2, 1997, pp. 113-121. 